\title{
A remote sensing-based dataset to characterize the ecosystem functioning and functional diversity of a Biosphere Reserve: Sierra Nevada (SE Spain)
}

5 Beatriz P. Cazorla ${ }^{1,2}$, Javier Cabello ${ }^{1,2}$, Andrés Reyes ${ }^{1}$, Emilio Guirado ${ }^{1,3}$, Julio Peñas ${ }^{1,4}$, Antonio J. Pérez-Luque ${ }^{5,6}$, Domingo Alcaraz-Segura ${ }^{1,4,5}$

${ }^{1}$ Andalusian Center for the Assessment and Monitoring of Global Change, University of Almería, 04120, Almería, Spain

2 Department of Biology and Geology, University of Almería, 04120, Almería, Spain

${ }^{3}$ Andalusian Research Institute in Data Science and Computational Intelligence, University of Granada, 18071, Granada, Spain.

4 Department of Botany, University of Granada, Av. de Fuentenueva, s/n 18071, Granada, Spain

5 iecolab. Andalusian Institute for Earth System Research (IISTA-CEAMA) - University of Granada, Avda. Mediterráneo s/n, E-18006, Granada, Spain.

6 Terrestrial Ecology Research Group, Department of Ecology, Faculty of Science, University of Granada, Av. Fuentenueva

s/n, Granada, E-18071 Spain

Correspondence to: Beatriz P. Cazorla (b.cazorla@ual.es) and Domingo Alcaraz-Segura (dalcaraz@ugr.es)

\section{Abstract}

Conservation Biology faces the challenge of safeguarding the ecological processes that sustain biodiversity. Characterization and evaluation of these processes can be carried out through attributes or functional traits related to the exchanges of matter and energy between vegetation and the atmosphere. Nowadays, the use of satellite imagery provides useful methods to produce a spatially continuous characterization of ecosystem functioning and (Spain) from the vegetation greenness dynamics captured through the spectral vegetation index EVI (Enhanced Vegetation Index) since 2001 to 2018 (product MOD13Q1.006 from MODIS sensor). First, we provided three Ecosystem Functional Attributes (EFAs) (i.e., descriptors of annual primary production, seasonality, and phenology of carbon gains), as well as their integration into a synthetic mapping of Ecosystem Functional Types (EFTs). Second, we provided two measures of functional diversity: EFT richness and EFT rarity. Finally, in addition to the yearly maps, we calculated interannual summaries, i.e., means and inter-annual variabilities. Examples of research and management applications of these data sets are also included to highlight the value of EFAs and EFTs to improve the understanding and monitoring ecosystem processes across environmental gradients. The datasets are available in two open-source sites (PANGAEA:

https://doi.pangaea.de/10.1594/PANGAEA.904575 (Cazorla et al. 2019) and
http://obsnev.es/apps/efts_SN.html), and bring to scientists, managers and the general public valuable information on the first characterization of the functional diversity at ecosystem level developed in a Mediterranean hotspot. Sierra Nevada represents an exceptional ecology laboratory of field conditions, where a long-term monitoring (LTER) program was established 10 years ago. The data availability on biodiversity, climate, ecosystem services,

40 hydrology, land-use changes and management practices from Sierra Nevada, will allow to explore the relationships between these other environmental data and ecosystem functional data that we provide in this work.

\section{Introduction}

45 A better characterization of the functional dimension of biodiversity is required to develop management approaches that ensure nature contributions to human well-being (Jax, 2010). To achieve this goal, it is necessary to have a set of essential variables that characterize and monitor ecosystem functioning (Pereira et al., 2013). Such variables are basic to understand the dynamics of ecological systems (Petchey and Gaston, 2006), the links 
between biological diversity and ecosystem services (Balvanera et al., 2006; Haines-Young and Potschin, 2010), and the mechanisms of ecological resilience (Mouchet et al., 2010). In addition, the use of ecosystem functioning variables has been demanded to assess functional diversity at large scales with the aim of measuring the Biosphere integrity (Mace et al., 2014; Steffen et al., 2015), one of the most challenging planetary boundaries to quantify (Steffen et al., 2015). Despite the importance of ecosystem functioning variables, and the conceptual frameworks developed to promote their use (Pettorelli et al., 2018), they have seldom been incorporated to ecosystem monitoring in protected areas (but see Alcaraz-Segura et al., 2009; Fernández et al., 2010; Cabello et al., 2016).

Characterization and evaluation of ecosystem functioning can be carried out through attributes or functional traits related to the exchanges of matter and energy between vegetation and the atmosphere (Mueller-Dombois and Ellenberg, 1974). Nowadays, the use of satellite imagery provides useful methods to produce a spatially continuous characterization of ecosystem functioning and functional diversity at local (Fernández et al., 2010), regional (Alcaraz-Segura et al., 2006, 2013) or global scales (Ivits et al., 2013). Theoretical and empirical models support the relationship between spectral indices derived from satellite images (e.g. Enhanced Vegetation Index, EVI) and essential functional variables of ecosystems, such as primary production, evapotranspiration, surface temperature, or albedo (Running et al., 2000; Pettorelli et al., 2005; Fernández et al., 2010; Lee et al., 2013).

65 Among them, primary production is considered the most integrative and essential indicator of ecosystem functioning (Virginia and Wall, 2001; Pereira et al., 2013), since it has an important role in the carbon cycle (i.e., it is the energy input to the trophic web and therefore, the driving force behind many ecological processes). Moreover, primary production offers a comprehensive response to environmental changes, and constitutes a synthetic indicator of ecosystem health (Costanza et al., 1992; Skidmore et al., 2015).

To characterize ecosystem functioning through spectral vegetation indices, we can use the approach based on Ecosystem Functional Types (EFTs), defined as patches of the land surface that share similar dynamics in the exchanges of matter and energy between the biota and the physical environment (Paruelo et al., 2001; AlcarazSegura et al., 2006). EFTs are derived from three Ecosystem Functional Attributes (EFAs) that describe the

75 seasonal dynamics of carbon gains: annual mean (a surrogate of annual primary production, the most essential and integrative indicator of ecosystem functioning), annual standard deviation (a descriptor of seasonality or the differences between the growing and non-growing seasons), and the annual date of maximum (a phenological indicator of when in the year is the growing period centered). Since the concept appeared in 2001 (Paruelo et al., 2001), the EFT approach (or equivalent approaches) has exponentially grown to characterize functional

80 heterogeneity from local to global scales (Alcaraz-Segura et al., 2006; Karlsen et al., 2006; Duro et al., 2007; Fernández et al., 2010; Geerken 2009; Alcaraz-Segura et al., 2013; Ivits et al., 2013; Cabello et al., 2013; PérezHoyos et al., 2014; Müller et al., 2014; Wang and Huang, 2015; Villarreal et al., 2018; Coops et al., 2018; Mucina, 2019).

85 This article aims to illustrate how EFAs and EFTs can be used to assess the spatio-temporal heterogeneity and inter-annual variability of ecosystem functioning in protected areas based on the vegetation dynamics captured through spectral vegetation indices (e.g. EVI). We introduce as a proof of concept the case of Sierra Nevada Biosphere reserve (SE Spain) from 2001 to 2018. First, for each year, we provide three Ecosystem Functional Attributes (EFAs) (i.e., annual primary production, seasonality and phenology of carbon gains), as well as their

90 integration into a synthetic mapping of Ecosystem Functional Types (EFTs). Second, we present two measures of functional diversity: EFT richness and EFT rarity. Finally, in addition to the yearly maps, we calculated interannual summaries, i.e., inter-annual means and inter-annual variability, to show the average conditions as well as the most stable and variable zones along the period (workflow in Fig. 2).

\section{$95 \quad 2$ Methods}

\subsection{Site Description}

Sierra Nevada (Andalusia, SE Spain) is a mountainous region covering more than $2,000 \mathrm{~km}^{2}$ with an elevation range of between 860 and 3,482 m a.s.1 (Fig. 1). It is considered one of the most important biodiversity hotspots 
100 in the Mediterranean region (Blanca et al., 1998; Cañadas et al., 2014), hosting 105 endemic plant species for a total of 2,353 taxa of vascular plants (33\% and 20\% of Spanish and European flora, respectively; Lorite 2016). Forest cover in Sierra Nevada is dominated by pine plantations (Pinus halepensis Mill., Pinus pinaster Ait., Pinus nigra Arnold subsp. salzmannii (Dunal) Franco, and Pinus sylvestris L.) covering approximately 40,000 ha. Most of them were planted in the period 1960-1980. The main native forests of Sierra Nevada are dominated by the evergreen holm oak Quercus ilex subsp. ballota (Desf.) Samp. occupying low and medium mountain areas $(8,800$ ha.), and by the deciduous Pyrenean oak Quercus pyrenaica Willd ranging from 1,100 to 2,000 m a.s.1. (about 2,000 ha). Autochthonous pine Pinus sylvestris L. var. nevadensis H. Christ forests can also be found in small patches with low tree cover in the treeline. Above the treeline, plant communities of the Oromediterranean and Crioromediterranean belts (above 1,800-2,000 m.) are dominated by chamaephytes and hemicryptophytes 110 (scrublands, grasslands, and cliff and scree communities), being the habitat to many endemic species. Sierra Nevada receives legal protection and international recognition in multiple ways: MAB Biosphere Reserve (1986), Natural Park (1989),National Park (1999), Important Bird Area (2003), Special Area of Conservation (Natura 2000 network, 2012), and it is included in the IUCN Green List of Protected Areas (2014) and in the Spanish LTER network (Zamora et al. 2017). The main economic activities in this mountain region are agriculture, tourism, livestock raising, beekeeping, mining, and skiing (Bonet et al., 2010).

In Sierra Nevada, vegetation studies have mainly been developed considering a compositional perspective (phytosociological method) or successional perspective (vegetation series). These studies have been very useful for describing the vegetation heterogeneity at mesoscale (Loidi, 2017), for characterizing habitats of conservation importance (EU Directive 92/43/EEC), and for developing forest restoration policies (Valle et al., 2003). However, these approaches are difficult to monitor the effects of environmental changes and management actions, to understand the environmental gradients at protected area scale that drive biodiversity patterns, and to evaluate the role of ecosystems as suppliers of benefits to society (Cabello et al., 2019).

\subsection{Satellite images of Vegetation Indices (MOD13Q1 data product)}

125 The characterization of ecosystem functioning in Sierra Nevada was based on the temporal dynamics of the Enhanced Vegetation Index (EVI) from 2001 to 2018. Specifically, we used the MOD13Q1.006 product of the MODIS sensor (Moderate Resolution Imaging Spectroradiometer) on board NASA's Terra satellite (Didan 2015). This product provides maximum value composite images every 16 days (23 images per year) at 231 meters spatial resolution and are downloadable from NASA's LP DAAC (Land Processes Distributed Active Archive Center) (http://lpdaac.usgs.gov/lpdaac/get_data) and in Google Earth Engine (DOI: https://doi.org/10.5067/MODIS/MOD13Q1.006 ). Values of EVI*10,000 are given as real numbers between 0 and 10,000 .

\subsection{Calculating Ecosystem Functional Attributes (EFAs)}

135 We identified three EFAs that are known to capture most of the variance in the time series of vegetation indices and that are biologically meaningful (Paruelo et al., 2001; Alcaraz-Segura et al., 2006, 2009). These attributes were calculated from the EVI seasonal curve or annual dynamics. From the EVI seasonal curve of each year, we identified three functional attributes: the EVI annual mean (EVI_mean; an estimator of primary production), the EVI seasonal Standard Deviation (EVI_sSD; a descriptor of seasonality, i.e., the differences between the growing

140 and non-growing seasons), and the date of maximum EVI (EVI_DMAX; a phenological indicator of the month with maximum EVI) (Fig.3). To summarize the EFAs of the 2001-2018 period, we calculated the inter-annual mean and the inter-annual variability for each attribute.

\subsection{Identifying Ecosystem Functional Types (EFTs)}

145 EFTs were identified by synthesizing in a single map the variability contained in the three EFAs following a similar approach to Alcaraz-Segura et al. (2013). The range of values of each EFA was divided into four intervals, giving a potential number of 64 EFTs $(4 \times 4 \times 4)$. For EVI_DMAX, the four intervals agreed with the four seasons of the year. For EVI_mean and EVI_sSD, we extracted the first, second, and third quartiles for each year and then 
calculated the inter-annual mean of each quartile (means of the 18-year period) (Table 1). These fixed limits between EFT classes were applied to each year. To summarize the EFTs of the 2001-2018 period, we calculated the most frequent EFT of the period (i.e., the EFT mode for each pixel). To name EFTs, we used two letters and a number: the first capital letter indicates net primary production (EVI_mean), increasing from A to D; the second small letter represents seasonality (EVI_SD), decreasing from a to d; the numbers are a phenological indicator of the growing season (EVI_DMAX), with values 1-spring, 2-summer, 3-autumn, 4-winter.

\subsection{Characterizing Ecosystem Functional Diversity}

To characterize ecosystem functional diversity, we used EFT richness and EFT rarity. EFT richness was calculated for each year by counting the number of different EFTs in a 4×4-pixel moving window (924 x $924 \mathrm{~m}$ ) around each pixel (top-left center pixel of the $4 \times 4$ Kernel) (modified from Alcaraz-Segura et al., 2013). Then, the average richness map of all years was obtained. EFT rarity was calculated for each year as the relative extension of each EFT compared to the most abundant EFT (Equation 1) (Cabello et al., 2013). Then, the average rarity map of all years was obtained.

$$
\text { Rarity of EFTi }=(\text { Area_EFTmax }- \text { Area_EFTi)/Area_EFTmax }(\text { Equation 1) }
$$

where Area_EFTmax is the area occupied by the most abundant EFT and Area_EFT $i$ is the area of the $i$ EFT being evaluated, with $i$ ranging from 1 to 64 .

\subsection{Stability in ecosystem functioning}

To identify the most stable and variable areas (either due to inter-annual fluctuations or to directional trends) in ecosystem functioning, we provide three approaches. First, we calculated the inter-annual variability of each EFA (coefficient of variation for EVI_mean and EVI_sSD, and circular standard deviation for EVI_DMAX). Second, we recorded the number of different EFTs that occurred in the same pixel in the period 2001-2018. Third, to 175 consider the changes not only at the pixel but also at the landscape level, the Jaccard similarity index (Jaccard, 1901) (Equation 2) was used in 4×4-pixel moving windows ( $924 \times 924 \mathrm{~m}$ ).

$$
\text { Jaccard Index }=(\text { the number in both sets }) /(\text { the number in either set }) * 100
$$

180 The same formula in notation is (Equation 3):

$$
J(X, Y)=|X \cap Y| /|X \cup Y|
$$

In Steps:

1) Count the number of EFTs which are shared between both windows; 2) Count the total number of EFTs in both windows (shared and unshared); 3) Divide the number of shared EFTs 1) by the total number of EFTs 2); 4) Multiply the number found in 3) by 100 .

This measure represents how similar is the EFT composition that occurs in each window throughout the entire time series (2001-2018). For each window, the Jaccard index was calculated among all possible combinations of years and then the interannual average of all calculated indices was obtained. Dissimilarity was calculated as 190 (Equation 4):

$$
\text { Dissimilarity }=1 \text { - Jaccard Index }
$$

Dissimilarity values range from 0 to 1 , with 1 being the highest degree of dissimilarity in composition and relative abundance of EFTs and 0 being absent. 


\section{Results and Discussion}

\subsection{Available dataset}

Overall, the collection of datasets provides a characterization of ecosystem functioning and ecosystem functional diversity in Sierra Nevada Biosphere Reserve (SE Spain) through remote sensing. To broaden the use of data, first, we provide data in .tif format. Second, we have incorporated rendered versions of all layers as required by Google Earth Pro (called "filename..._forGoogleEarthVisualization.tif") for visualization. And third, we have also developed an ad-hoc visualization platform for all the layers.

All data are available yearly (2001-2018) and summarized for the period, in EPSG:4326 WGS84.

The dataset is structured in three main subsets of variables: Ecosystem Functional Attributes, Ecosystem Functional Types, and Ecosystem Functional Diversity (see Table 2). For each variable there are two groups of data (two subfolders): one containing the yearly variables, and another one containing the summaries for the 18year period.

215

\subsection{Ecosystem Functional Attributes patterns}

Functional attributes of productivity, seasonality and phenology showed a clear altitudinal pattern. Productivity (EVI_mean) was much lower in the Crioro- and Oromediterranean bioclimatic belts than in the Supra- and Mesomediterranean belts. Productivity also decreased from west to east (Fig. 4a). Seasonality (EVI_sSD) was high in the Supramediterranean, decreasing in Meso-, and Thermomediterranean belts, and in Crioro- and Oromediterranean (Fig. 4b). Phenology (EVI_DMAX) was characterized by a dominant summer peak in vegetation greenness in the Crioro- and Oromediterranean belts, and a late spring peak in the Supra- and Mesomediterranean belts. Dry and semi-arid thermomediterranean areas of the south and east showed greeness peaks in early autumn and winter months (Fig. 4c).

\subsection{Ecosystem Functional Type patterns}

As a result of the combination of the three functional attributes of the canopy, productivity, seasonality and phenology, represented in Fig. 4 a-c, we obtained the EFTs map (Fig. 4d) that includes a synthetic characterization of the spatial patterns of ecosystem functioning. A total of 64 classes were observed. The most abundant EFT presented the maximum greenness in spring, with productivity values from low to intermediate and with all possible combinations of seasonality: $\mathrm{Aa} 1, \mathrm{Ba} 1, \mathrm{Cb} 1, \mathrm{Cd} 1, \mathrm{Ba} 1$, and $\mathrm{Cc} 1$ accumulated $30 \%$ of the surface. On the contrary, the rarest EFTs were Ba4, Aa4 characterized by medium or low productivity, high seasonality and maximum greenness in winter.

Crioro and oromediterranean areas presented EFTs with low and intermediate productivity, high seasonality and moments of maximum greenness mainly in summer, but also in spring. Here, extreme conditions characterized by scarce soil (Peinado et al., 2019), high solar radiation, extreme temperatures, winds, snow and ice, give rise to a short vegetative period. This results in scarce vegetation cover, controlled by low temperatures, which can only occur in summer, being the plant growth time, hence these areas have been referred to as "cold desert" (Blanca et al., 2019). The supra- and mesomediterranean levels had associated EFTs of intermediate-high productivity, medium-low seasonality and maximum green moment in spring and autumn (e.g., Cc1-3) (Fig. 4d). The supramediterranean is characterized by the presence of deciduous species, e.g., oak groves associated with the most productive and seasonal ecosystem functional type of the study area, with maximum in spring (EFT Da1). In the dry and semi-arid thermomediterranean of the eastern end, characterized by thermophilic species, which hardly suffer from frost, a different functional behaviour of the ecosystems was detected. The functioning of this area showed low values of productivity, medium-low seasonality and maximum greenness of the vegetation in spring or winter (e.g., Ac1-4). Here, the main control of ecosystem functioning is water availability, presenting plant species with a fast response to scarce water inputs (Cabello et al., 2012). 


\subsection{Stability in ecosystem functioning}

The interannual variability ranged from 1 to 17 different EFTs over the 18-year period in the same pixel (Fig. 5a). The number of EFTs observed in the same pixel over 18 years was higher in the supra- and mesomediterranean levels, coinciding with the altitudinal range where interannual climate variability is most affected (e.g., they may present a lot of snow in cold years and be affected by drought in dry and warm years). The eastern end of the semi-arid thermomediterranean also highlighted with high inter-annual variability, where there exists a greater climate fluctuation and where small changes in precipitation produce large changes in the dynamics of primary production (Houérou et al., 1988; Cabello et al., 2012), as well as the area burned in 2005 near Lanjarón, where the fire eliminated the vegetation that has been regenerating since then. On the other hand, the most stable vegetation types interannual, i.e., those that changed the least during the period, were located in the mesooromediterranean and crioromediterranean levels, specifically, the oak and borreguil vegetation types, ecosystems that are not subject to anthropic presence (e.g., low forest management and low presence of livestock).

The results of the inverse of the Jaccard coefficient to obtain the dissimilarity or functional changes between years in the composition of EFTs over the 2001-2018 period (Fig. 5b), showed an altitudinal pattern where the dissimilarity between EFTs was lower in the oro and cryoromediterranean levels, as well as in the mesomediterranean oak groves (functional stability already shown by other authors, i. e. Requena-Mullor et al, 270 2018). This pattern of dissimilarity increased towards lower levels, finding the highest values of dissimilarity (or greater change) in areas where changes in land use and management are major (Zamora et al., 2016), such as autochthonous pine forests on dolomites, coniferous repopulations and meso- and thermomediterranean holm oaks. In addition, the eastern end of the Sierra Nevada had an area with low dissimilarity values, that is, where there were not many changes over the years and when they occurred they were towards very similar EFTs.

\subsection{Functional diversity at ecosystem level}

Richness oscillated between 1 and 13 EFTs. Highest EFT richness was observed in the supra- and mesomediterranean, particularly in the southern face of the Sierra (Fig. 5c), where the number of vegetation series is also greater than in the rest of the bioclimatic floors (Valle et al., 2003). The presence EFTs hotspots mainly in the mid-mountain, and particularly in the southern face, could be related to two factors. On the one hand, many Mediterranean mountains show high values of beta diversity up to 1750-1800 m (Wilson and Schmida, 1984), when there is an important structural and compositional replacement of their vegetation. On the other hand, in the middle mountain and especially in its southern face, there is a very diverse mosaic of different types of natural

285 vegetation mixed with different types of reforestation, traditional crops and uses (Camacho et al., 2002), which gives them the characteristic of multifunctional landscapes from the point of view of the provision of ecosystem services (García-Nieto et al., 2013; Mastrangelo et al., 2014; Cabello et al., 2019). Molero Mesa et al., (1996) and Fernández Calzado et al., (2012) indicated that Sierra Nevada species richness decreases with altitude, while endemic taxa increases (Blanca et al., 2019). Something similar can be observed in the functional diversity of ecosystems, since the maximum richness is found in areas of medium altitude. The areas with the lowest EFT richness were located in the oro and crioromediterranean levels, and in the eastern semi-arid thermomediterranean extreme, where the harsh soil and climatic conditions (Peinado et al., 2019) diminish floristic diversity although their endemicity increases (Fernández Calzado et al., 2012). The lowest values of EFT richness (richness 4-5) were found in the supramediterranean oak groves, (as in Dionisio et al., 2012; Requena-Mullor et al., 2018) maybe 295 due to the internal homogeneity of their environmental conditions and their floristic composition (Pérez-Luque et al., 2015, Requena-Mullor et al., 2018).

EFT rarity was highest in the crioromediterranean level, overlapping the area with the highest concentration of endemisms (Cañadas et al., 2014; Peñas et al., 2019) (Fig. 5d). Crioromediterranean vegetation develops under a very particular ecological conditions that determine uncommon types of ecosystem functioning (rarity 0.6; Fig. $5 \mathrm{~d}$ ), such as, for example, in relatively mobile rocks and canchales located on steep slopes, where the percentage of rarity or compositional endemicity rises to $80 \%$ (Blanca and Algarra, 2011). EFT rarity was also high in the eastern end of the semi-arid thermomediterranean level, located in the biogeographic sector of Almeria (Peñas et 
al., 2019) with a high concentration of endemisms typical of the Desert of Tabernas (Mota et al., 2004). In the oromediterranean, EFT rarity decreased and reached its minimum, due to the great extension in the Sierra Nevada of this bioclimatic level, which made its functioning not appear as rare, and increasing again in the supra- and mesomediterranean (Fig. 5d). The most rare supra- and mesomediterranean vegetation types corresponded to coniferous and holm oak repopulations (rarity 0.6 ). The high rarity of coniferous repopulations may be due to disturbances or management interventions that give rise to unique functions in the different masses of conifers.

310 On the other hand, the rarity in holm oaks may be due to their exclusive functioning, i.e. they have very specific associated EFTs (e.g., Cc1, Dc1). However, the rarity of the different vegetation types (between 0.45 and 0.64 ) was far from the maximum possible (1).

\section{Data applications for research and conservation / Example of data usage}

315 Ecological research based on spectral vegetation indices plays an important role in biodiversity conservation (Cabello et al., 2012; Pettorelli, 2016, 2018) and management (Pelkey et al., 2003; Cabello et al., 2016) and for the study of biodiversity and ecosystems responses to environmental changes (Alcaraz-Segura et al., 2017; PérezLuque et al. 2015). In fact, numerous studies have demonstrated the usefulness of satellite image time series to evaluate the functional changes in ecosystems at regional scale (Alcaraz-Segura et al., 2010) and at the protected area level (Alcaraz-Segura et al., 2009; Lourenço et al., 2018). Recently, the use of EFAs derived from spectral indices of vegetation in species distribution models, has made it possible to evaluate with great spatial and temporal precision the suitability of habitat for plant species (Arenas-Castro et al., 2018) and animals (RequenaMullor et al., 2017; Regos et al., 2019) and may even anticipate expected changes in the distribution of plant species threatened as a consequence of climate change (Alcaraz-Segura et al., 2017). In addition, based on the EFAs, a monitoring programme of the Spanish National Parks Network has been designed to identify changes and anomalies in functioning, informing managers of the health and conservation status of ecosystems (Cabello et al., 2016).

Furthermore, EFTs have been used to characterize spatial and temporal heterogeneity of ecosystem functioning at local and regional scales (Fernández et al., 2010; Cabello et al., 2013); to describe biogeographical patterns (Alcaraz-Segura et al., 2006; Ivits et al., 2013); to evaluate the environmental and human controls of ecosystem functional diversity (Alcaraz-Segura et al., 2013); to identify priorities for Biodiversity Conservation (Cazorla et al., 2019); to assess the representativeness environmental networks (Villarreal et al., 2018); to assess the effects of land-use changes on ecosystem functioning (Oki et al., 2013); or to improve weather forecast models (Lee et al., 2013; Müller et al., 2014).

The data sets that we are providing give to the scientific community valuable information of the first characterization of the functional diversity at ecosystem level developed in the entire protected area. We provided a detailed characterization of the functional diversity at ecosystem level for Sierra Nevada, that could be useful to monitor the response of ecosystems to global change and management actions, to understand the ecosystem functioning and functional diversity across the environmental gradients at protected area scale, and to evaluate the role of ecosystems in providing ecosystem services (Cabello et al., 2019). Sierra Nevada is also a long-term ecological laboratory established 10 years ago (Zamora et al. 2016, 2017), that have available data on biodiversity, climate, ecosystem services, hydrology, land-use changes and management practices from Sierra Nevada. This

345 will allow to explore the relationships between these other environmental data with the ecosystem functional data that we provide.

\section{Data availability}

The datasets described in this article are available in open-access sources. To broaden their use, first, we provide data in .tif format. Second, we have incorporated rendered versions of all layers as required by Google Earth Pro (called "filename..._forGoogleEarthVisualization.tif") for visualization. And third, we have also developed an adhoc visualization platform for all the layers. Datasets available for download in PANGAEA 

http://obsnev.es/apps/efts_SN.html.

The MODIS database used in this work are maintained by NASA (satellite Terra, sensor MODIS, product MOD13Q1.006), and the geospatial datasets of Sierra Nevada Park are included in public database of the Andalusian regional government (REDIAM).

\section{Conclusion}

365 This dataset provides a characterization of ecosystem functioning and ecosystem functional diversity in Sierra Nevada Biosphere Reserve (SE Spain) through the analysis of time series of satellite images of spectral vegetation indices as surrogates of the carbon gains dynamics. First, three Ecosystem Functional Attributes (EFAs) describe the spatial and inter-annual variability in productivity, seasonality and phenology of vegetation photosynthetic activity. Second, the combination of these EFAs into a synthetic classification, i.e. Ecosystem Functional Types

370 (EFTs), integrates in a single map the spatial heterogeneity of these descriptors of the seasonal dynamics of carbon gains. Finally, by using EFTs as biological entities, the spatial patterns of ecosystem functional diversity were assessed by means of EFT richness and EFT rarity, as well as the inter-annual variability in ecosystem functioning through EFT inter-annual variability and EFT inter-annual dissimilarity.

375 Ecosystem Functional Types approach improve the understanding of ecosystem processes through environmental gradients and provide both the scientific community with valuable information of the first characterization of the functional diversity at ecosystem level developed in the entire protected area.

\section{Author contributions}

DAS, JC, JP and BPC designed the study, and DAS, JC, JP coordinated it. BPC, AR and EG processed data and produced the associated data sets presented in this paper. BPC prepared the manuscript with contributions from all authors. BPC and EG prepared the final figures. AJPL design and made the application to visualize the data.

Competing interests. The authors declare that they have no conflict of interest.

Acknowledgements. This study was supported by Plan Propio program PhD of University of Almería, it was also developed as part of the H2020 project "ECOPOTENTIAL: Improving future ecosystem benefits through earth observations" (http://www.ecopotential-project.eu/), which has received funding from the European Union's Horizon 2020 research and innovation programme under grant agreement No 641762; and project LIFEADAPTAMED (LIFE14 CCA/ES/000612): "Protection of key ecosystem services by adaptive management of Climate Change endangered Mediterranean socio-ecosystems". E.G. was supported by the Spanish Ministry of Science under the project TIN2017-89517-P.

\section{References}

Alcaraz-Segura, D., Paruelo, J. and Cabello, J.: Identification of current ecosystem functional types in the Iberian Peninsula, Global Ecology and Biogeography, 15(2), 200-212, doi:10.1111/j.1466-822X.2006.00215.x, 2006.

Alcaraz-Segura, D., Cabello, J., Paruelo, J. M. and Delibes, M.: Use of Descriptors of Ecosystem Functioning for Monitoring a National Park Network: A Remote Sensing Approach, Environmental Management, 43(1), 38 48, doi:10.1007/s00267-008-9154-y, 2009. 
400 Alcaraz-Segura, D., Chuvieco, E., Epstein, H. E., Kasischke, E. S. and Trishchenko, A.: Debating the greening vs. browning of the North American boreal forest: differences between satellite datasets, Global Change Biology, 16(2), 760-770, 2010.

Alcaraz-Segura, D., Paruelo, J. M., Epstein, H. E. and Cabello, J.: Environmental and Human Controls of Ecosystem Functional Diversity in Temperate South America, Remote Sensing, 5(1), 127-154, doi:10.3390/rs5010127, 2013.

Alcaraz-Segura, D., Lomba, A., Sousa-Silva, R., Nieto-Lugilde, D., Alves, P., Georges, D., Vicente, J. R. and Honrado, J. P.: Potential of satellite-derived ecosystem functional attributes to anticipate species range shifts, International Journal of Applied Earth Observation and Geoinformation, 57, 86-92, doi:10.1016/j.jag.2016.12.009, 2017.

410 Arenas-Castro, S., Gonçalves, J., Alves, P., Alcaraz-Segura, D. and Honrado, J. P.: Assessing the multi-scale predictive ability of ecosystem functional attributes for species distribution modelling, PLOS ONE, 13(6), e0199292, doi:10.1371/journal.pone.0199292, 2018.

Balvanera, P., Pfisterer, A. B., Buchmann, N., He, J.-S., Nakashizuka, T., Raffaelli, D. and Schmid, B.: Quantifying the evidence for biodiversity effects on ecosystem functioning and services, Ecology Letters, 9(10), 415 1146-1156, doi:10.1111/j.1461-0248.2006.00963.x, 2006.

Blanca, G. and Algarra, J. A.: Flora del espacio natural de Sierra Nevada, Jornadas Estatales de estudio y divulgación de la flora de los Parques Nacionales y Naturales. CAM, Alcoy, 21-36, 2011.

Blanca, G., Cueto, M., Martínez-Lirola, M. J. and Molero-Mesa, J.: Threatened vascular flora of Sierra Nevada (Southern Spain), Biological Conservation, 85(3), 269-285, doi:10.1016/S0006-3207(97)00169-9, 1998.

420 Blanca, G., Cueto, M. Romero A.T.: Rareza y endemicidad en la flora vascular de Sierra Nevada, in Biología de la conservación de plantas en Sierra Nevada: Principios y retos para su preservación, pp. 325-343, Editorial Universidad de Granada., 2019.

Bonet, F. J., Pérez Luque, A. J., Moreno Llorca, R. and Zamora Rodríguez, R. J.: Sierra Nevada Global Change Observatory. Structure and Basic Data, 2010.

425 Cabello, J., Fernández, N., Alcaraz-Segura, D., Oyonarte, C., Piñeiro, G., Altesor, A., Delibes, M. and Paruelo, J. M.: The ecosystem functioning dimension in conservation: insights from remote sensing, Biodivers Conserv, 21(13), 3287-3305, doi:10.1007/s10531-012-0370-7, 2012.

Cabello, J., Lourenço, P., Reyes-Díez, A. and Alcaraz-Segura, D.: Ecosystem services assessment of national parks networks for functional diversity and carbon conservation strategies using remote sensing, Earth Observation of Ecosystem Services, 179, 2013.

Cabello, J., Alcaraz-Segura, D., Reyes-Díez, A., Lourenço, P., Requena-Mullor, J., Bonache, J., Castillo, P., Valencia, S., Naya, J., Ramírez, L. and Serrada, J.: Sistema para el Seguimiento del funcionamiento de ecosistemas en la Red de Parques Nacionales de España mediante Teledetección, Revista de Teledetección, 46, 119-131, doi:10.4995/raet.2016.5731, 2016

435 Cabello, J., López-Rodríguez, M., Pacheco-Romero, M., Torres-García, M.T., Reyes-Díez, A.: Valores y argumentos para la conservación de la diversidad vegetal de Sierra Nevada, , in Biología de la conservación de plantas en Sierra Nevada: Principios y retos para su preservación, pp. 345-361, Editorial Universidad de Granada., 2019.

Calzado, M. R. F., Mesa, J. M., Merzouki, A. and Porcel, M. C.: Vascular plant diversity and climate change in the upper zone of Sierra Nevada, Spain, Plant Biosystems - An International Journal Dealing with all Aspects of Plant Biology, 146(4), 1044-1053, doi:10.1080/11263504.2012.710273, 2012.

Camacho Olmedo, M. T., García Martínez, P., Jiménez Olivencia, Y., Menor Toribio, J. and Paniza Cabrera, A.: Dinámica evolutiva del paisaje vegetal de la Alta Alpujarra granadina en la segunda mitad del siglo XX, 2002. 

282-291, doi:10.1016/j.biocon.2013.12.007, 2014.

Cazorla, B. P., Cabello, J., Peñas, J., Guirado, E.., Reyes-Díez, A. and Alcaraz-Segura, D.: Funcionamiento de la vegetación y diversidad funcional de los ecosistemas de Sierra Nevada, in Biología de la conservación de plantas en Sierra Nevada: Principios y retos para su preservación, pp. 325-343, Editorial Universidad de Granada., 2019.

Cazorla, B. P., Cabello, J., Reyes-Díez, A., Guirado, E., Peñas, J., Pérez-Luque, A J., Alcaraz-Segura, D.: Ecosystem functioning and functional diversity of Sierra Nevada (SE Spain). University of Almería and Granada, PANGAEA, https://doi.pangaea.de/10.1594/PANGAEA.904575, 2019.

Coops, N. C., Kearney, S. P., Bolton, D. K. and Radeloff, V. C.: Remotely-sensed productivity clusters capture global biodiversity patterns, Scientific reports, 8, 2018a.

Coops, N. C., Kearney, S. P., Bolton, D. K. and Radeloff, V. C.: Remotely-sensed productivity clusters capture global biodiversity patterns, Sci Rep, 8(1), 16261, doi:10.1038/s41598-018-34162-8, 2018b.

Costanza, R., Norton, B. G. and Haskell, B. D.: Ecosystem Health: New Goals for Environmental Management, Island Press., 1992.

460 Didan, K.: MOD13Q1 MODIS/Terra vegetation indices 16-day L3 global 250m SIN grid V006, NASA EOSDIS Land Processes DAAC, 2015.

Dionisio, M. A., Alcaraz-Segura, D. and Cabello, J.: Satellite-based monitoring of ecosystem functioning in protected areas: recent trends in the oak forests (Quercus pyrenaica Willd.) of Sierra Nevada (Spain), International Perspectives on Global Environmental Change, 355, 37, 2012.

465 Directive, H.: Council Directive 92/43/EEC of 21 May 1992 on the conservation of natural habitats and of wild fauna and flora, Official Journal of the European Union, 206, 7-50, 1992.

Duro, D. C., Coops, N. C., Wulder, M. A. and Han, T.: Development of a large area biodiversity monitoring system driven by remote sensing, Progress in Physical Geography: Earth and Environment, 31(3), 235-260, doi:10.1177/0309133307079054, 2007.

470 Fernández, N., Paruelo, J. M. and Delibes, M.: Ecosystem functioning of protected and altered Mediterranean environments: A remote sensing classification in Doñana, Spain, Remote Sensing of Environment, 114(1), 211220, doi:10.1016/j.rse.2009.09.001, 2010

Fernández Calzado, M. R., Molero Mesa, J., Merzouki, A., Casares Porcel, M.: Vascular plant diversity and climate change in the upper zone of Sierra Nevada, Spain. Plant Biosystems-An International Journal Dealing with all Aspects of Plant Biology, 146(4),1044-1053, doi:https://doi.org/10.1080/11263504.2012.710273, 2012.

García-Nieto, A. P., García-Llorente, M., Iniesta-Arandia, I. and Martín-López, B.: Mapping forest ecosystem services: From providing units to beneficiaries, Ecosystem Services, 4, 126-138, doi:10.1016/j.ecoser.2013.03.003, 2013.

Geerken, R. A.: An algorithm to classify and monitor seasonal variations in vegetation phenologies and their inter-annual change, ISPRS Journal of Photogrammetry and Remote Sensing, 64(4), 422-431, doi:10.1016/j.isprsjprs.2009.03.001, 2009.

Haines-Young, R. and Potschin, M.: The links between biodiversity, ecosystem services and human well-being, Ecosystem Ecology: A New Synthesis, doi:10.1017/CBO9780511750458.007, 2010.

Ivits, E., Cherlet, M., Mehl, W. and Sommer, S.: Ecosystem functional units characterized by satellite observed 
Jaccard, P.: Étude comparative de la distribution florale dans une portion des Alpes et des Jura, Bull Soc Vaudoise Sci Nat, 37, 547-579, 1901.

Jax, K.: Ecosystem Functioning, Cambridge University Press, Cambridge., 2010.

490 Karlsen, S. R., Elvebakk, A., Høgda, K. A. and Johansen, B.: Satellite-based mapping of the growing season and bioclimatic zones in Fennoscandia, Global Ecology and Biogeography, 15(4), 416-430, doi:10.1111/j.1466822X.2006.00234.X, 2006.

Le Houérou, H. N.: A probabilistic approach to assessing arid rangelands' productivity, carrying capacity and stocking rates, Drylands: sustainable use of rangelands into the twenty first century, 159-172, 1998.

495 Lee, S.-J., Berbery, E. H. and Alcaraz-Segura, D.: The impact of ecosystem functional type changes on the La Plata Basin climate, Adv. Atmos. Sci., 30(5), 1387-1405, doi:10.1007/s00376-012-2149-x, 2013.

Loidi, J.: The Vegetation of the Iberian Peninsula, Springer., 2017.

Lorite, J.: An updated checklist of the vascular flora of Sierra Nevada (SE Spain), Phytotaxa, 261(1), 1-57, 2016.

500 Lourenço, P., Alcaraz-Segura, D., Reyes-Díez, A., Requena-Mullor, J. M. and Cabello, J.: Trends in vegetation greenness dynamics in protected areas across borders: what are the environmental controls?, International Journal of Remote Sensing, 39(14), 4699-4713, doi:10.1080/01431161.2018.1466080, 2018.

Mace, G. M., Reyers, B., Alkemade, R., Biggs, R., Chapin, F. S., Cornell, S. E., Díaz, S., Jennings, S., Leadley, P., Mumby, P. J., Purvis, A., Scholes, R. J., Seddon, A. W. R., Solan, M., Steffen, W. and Woodward, G.:

505 Approaches to defining a planetary boundary for biodiversity, Global Environmental Change, 28, 289-297, doi:10.1016/j.gloenvcha.2014.07.009, 2014.

Mastrangelo, M. E., Weyland, F., Villarino, S. H., Barral, M. P., Nahuelhual, L. and Laterra, P.: Concepts and methods for landscape multifunctionality and a unifying framework based on ecosystem services, Landscape Ecol, 29(2), 345-358, doi:10.1007/s10980-013-9959-9, 2014.

510 Molero Mesa, J., Pérez Raya, F. and González-Tejero, M. R.: Catálogo y análisis florístico de la flora orófila de Sierra Nevada, Sierra Nevada. Conservación y Desarrollo Sostenible, 2, 271-276, 1996.

Mota, J. F., Sola, A. J., Jiménez-Sánchez, M. L., Pérez-García, F. and Merlo, M. E.: Gypsicolous flora, conservation and restoration of quarries in the southeast of the Iberian Peninsula, Biodiversity and Conservation, 13(10), 1797-1808, doi:10.1023/B:BIOC.0000035866.59091.e5, 2004.

515 Mouchet, M. A., Villéger, S., Mason, N. W. H. and Mouillot, D.: Functional diversity measures: an overview of their redundancy and their ability to discriminate community assembly rules, Functional Ecology, 24(4), 867876, doi:10.1111/j.1365-2435.2010.01695.x, 2010.

Mucina, L.: Biome: evolution of a crucial ecological and biogeographical concept, New Phytologist, 222(1), 97114, doi:10.1111/nph.15609, 2019.

Mueller-Dombois, D. and Ellenberg, D.: Aims and methods of vegetation ecology, Wiley New York., 1974.

Müller, O. V., Berbery, E. H., Alcaraz-Segura, D. and Ek, M. B.: Regional Model Simulations of the 2008 Drought in Southern South America Using a Consistent Set of Land Surface Properties, J. Climate, 27(17), 6754-6778, doi:10.1175/JCLI-D-13-00463.1, 2014.

Oki, T., Blyth, E. M., Berbery, E. H. and Alcaraz-Segura, D.: Land Use and Land Cover Changes and Their Impacts on Hydroclimate, Ecosystems and Society, in Climate Science for Serving Society: Research, Modeling and Prediction Priorities, edited by G. R. Asrar and J. W. Hurrell, pp. 185-203, Springer Netherlands, Dordrecht., 2013. 
Paruelo, J. M., Jobbágy, E. G. and Sala, O. E.: Current Distribution of Ecosystem Functional Types in Temperate South America, Ecosystems, 4(7), 683-698, doi:10.1007/s10021-001-0037-9, 2001.

Peinado, F. J. M., Morales, M. N. J. and Ondoño, E. F.: Los suelos de Sierra Nevada, su relación con la litología y la vegetación, in Biología de la conservación de plantas en Sierra Nevada: Principios y retos para su preservación, pp. 173-192, Editorial Universidad de Granada., 2019.

Pelkey, N. W., Stoner, C. J. and Caro, T. M.: Assessing habitat protection regimes in Tanzania using AVHRR NDVI composites: Comparisons at different spatial and temporal scales, International Journal of Remote Sensing, 24(12), 2533-2558, doi: 10.1080/01431160210155929, 2003.

Peñas, J., Sánchez, E. C. and del Río Sánchez, J.: Fitogeografía de Sierra Nevada e implicaciones para la conservación, in Biología de la conservación de plantas en Sierra Nevada: Principios y retos para su preservación, pp. 81-116, Editorial Universidad de Granada., 2019.

Pereira, H. M., Ferrier, S., Walters, M., Geller, G. N., Jongman, R. H. G., Scholes, R. J., Bruford, M. W., Brummitt, N., Butchart, S. H. M., Cardoso, A. C., Coops, N. C., Dulloo, E., Faith, D. P., Freyhof, J., Gregory, R. D., Heip, C., Höft, R., Hurtt, G., Jetz, W., Karp, D. S., McGeoch, M. A., Obura, D., Onoda, Y., Pettorelli, N., Reyers, B., Sayre, R., Scharlemann, J. P. W., Stuart, S. N., Turak, E., Walpole, M. and Wegmann, M.: Essential Biodiversity Variables, Science, 339(6117), 277-278, doi:10.1126/science.1229931, 2013.

Pérez-Hoyos, A., Martínez, B., García-Haro, F. J., Moreno, Á. and Gilabert, M. A.: Identification of Ecosystem Functional Types from Coarse Resolution Imagery Using a Self-Organizing Map Approach: A Case Study for Spain, Remote Sensing, 6(11), 11391-11419, doi:10.3390/rs61111391, 2014.

Pérez-Luque, A. J., Pérez-Pérez, R., Bonet-García, F. J. and Magaña, P. J.: An ontological system based on MODIS images to assess ecosystem functioning of Natura 2000 habitats: A case study for Quercus pyrenaica forests, International Journal of Applied Earth Observation and Geoinformation, 37, 142-151, doi:10.1016/j.jag.2014.09.003, 2015.

Petchey, O. L. and Gaston, K. J.: Functional diversity: back to basics and looking forward, Ecology Letters, 9(6), 741-758, doi:10.1111/j.1461-0248.2006.00924.x, 2006.

Pettorelli, N., Vik, J. O., Mysterud, A., Gaillard, J.-M., Tucker, C. J. and Stenseth, N. Chr.: Using the satellitederived NDVI to assess ecological responses to environmental change, Trends in Ecology \& Evolution, 20(9), 503-510, doi:10.1016/j.tree.2005.05.011, 2005.

Pettorelli, N., Wegmann, M., Skidmore, A., Mücher, S., Dawson, T. P., Fernandez, M., Lucas, R., Schaepman, M. E., Wang, T., O’Connor, B., Jongman, R. H. G., Kempeneers, P., Sonnenschein, R., Leidner, A. K., Böhm, M., He, K. S., Nagendra, H., Dubois, G., Fatoyinbo, T., Hansen, M. C., Paganini, M., Klerk, H. M. de, Asner, G. P., Kerr, J. T., Estes, A. B., Schmeller, D. S., Heiden, U., Rocchini, D., Pereira, H. M., Turak, E., Fernandez, N.,

560 Lausch, A., Cho, M. A., Alcaraz-Segura, D., McGeoch, M. A., Turner, W., Mueller, A., St-Louis, V., Penner, J., Vihervaara, P., Belward, A., Reyers, B. and Geller, G. N.: Framing the concept of satellite remote sensing essential biodiversity variables: challenges and future directions, Remote Sensing in Ecology and Conservation, 2(3), 122-131, doi:10.1002/rse2.15, 2016.

Pettorelli, N., Schulte to Bühne, H., Tulloch, A., Dubois, G., Macinnis-Ng, C., Queirós, A. M., Keith, D. A., Wegmann, M., Schrodt, F., Stellmes, M., Sonnenschein, R., Geller, G. N., Roy, S., Somers, B., Murray, N., Bland, L., Geijzendorffer, I., Kerr, J. T., Broszeit, S., Leitão, P. J., Duncan, C., Serafy, G. E., He, K. S., Blanchard, J. L., Lucas, R., Mairota, P., Webb, T. J. and Nicholson, E.: Satellite remote sensing of ecosystem functions: opportunities, challenges and way forward, Remote Sensing in Ecology and Conservation, 4(2), 7193, doi: $10.1002 / \mathrm{rse} 2.59,2018$.

570 Requena-Mullor, J. M., López, E., Castro, A. J., Alcaraz-Segura, D., Castro, H., Reyes, A. and Cabello, J.: Remote-sensing based approach to forecast habitat quality under climate change scenarios, PLOS ONE, 12(3), e0172107, doi:10.1371/journal.pone.0172107, 2017.

Requena-Mullor, J. M., Reyes, A., Escribano, P. and Cabello, J.: Assessment of ecosystem functioning from space: Advancements in the Habitats Directive implementation, Ecological Indicators, 89, 893-902, doi:10.1016/j.ecolind.2017.12.036, 2018. 
Running, S. W., Thornton, P. E., Nemani, R. and Glassy, J. M.: Global Terrestrial Gross and Net Primary Productivity from the Earth Observing System, in Methods in Ecosystem Science, edited by O. E. Sala, R. B. Jackson, H. A. Mooney, and R. W. Howarth, pp. 44-57, Springer New York, New York, NY., 2000.

Skidmore, A. K., Pettorelli, N., Coops, N. C., Geller, G. N., Hansen, M., Lucas, R., Mücher, C. A., O’Connor, B., Paganini, M., Pereira, H. M., Schaepman, M. E., Turner, W., Wang, T. and Wegmann, M.: Environmental science: Agree on biodiversity metrics to track from space, Nature, 523(7561), 403-405, doi:10.1038/523403a, 2015.

Steffen, W., Richardson, K., Rockström, J., Cornell, S. E., Fetzer, I., Bennett, E. M., Biggs, R., Carpenter, S. R., Vries, W. de, Wit, C. A. de, Folke, C., Gerten, D., Heinke, J., Mace, G. M., Persson, L. M., Ramanathan, V.,

585 Reyers, B. and Sörlin, S.: Planetary boundaries: Guiding human development on a changing planet, Science, 347(6223), 1259855, doi:10.1126/science.1259855, 2015.

Valle, F., Algarra, J. A., Arrojo, E., Asensi, A., Cabello, J., Cano, E., Cañadas Sánchez, E., Cueto, M., Dana, E. and Simón, D.: Mapa de series de vegetación de Andalucía, 2003.

Villarreal, S., Guevara, M., Alcaraz-Segura, D., Brunsell, N. A., Hayes, D., Loescher, H. W. and Vargas, R.: Ecosystem functional diversity and the representativeness of environmental networks across the conterminous United States, Agricultural and Forest Meteorology, 262, 423-433, doi:10.1016/j.agrformet.2018.07.016, 2018.

Virginia, R. A., Wall, D. H. and Levin, S. A.: Principles of ecosystem function, Encyclopedia of biodiversity, 2, $345-352,2001$.

Wang, Y. and Huang, F.: Identification and analysis of ecosystem functional types in the west of Songnen Plain, China, based on moderate resolution imaging spectroradiometer data, JARS, 9(1), 096096, doi:10.1117/1.JRS.9.096096, 2015.

Wilson, M. V. and Shmida, A.: Measuring beta diversity with presence-absence data, The Journal of Ecology, $1055-1064,1984$

Zamora Rodríguez, R. J., Pérez-Luque, A. J., Bonet, F. J., Barea-Azcón, J. M. and Aspizua, R.: Global Change Impacts in Sierra Nevada: Challenges for Conservation. Consejería de Medio Ambiente y Ordenación del Terriorio. Junta de Andalucía. 208 pp, 2016.

Zamora, R., Pérez-Luque, A. J., Bonet, F. J., Barea-Azcón, J. M., Aspizua, R., Sánchez-Gutiérrez, F. J., ... Henares-Civantos, I.: Global change impact in the sierra nevada long-term ecological research site (Southern Spain). Bulletin of the Ecological Society of America, 98(2), 157-164, https://www.jstor.org/stable/90002404, 2017. 


\section{Figures}

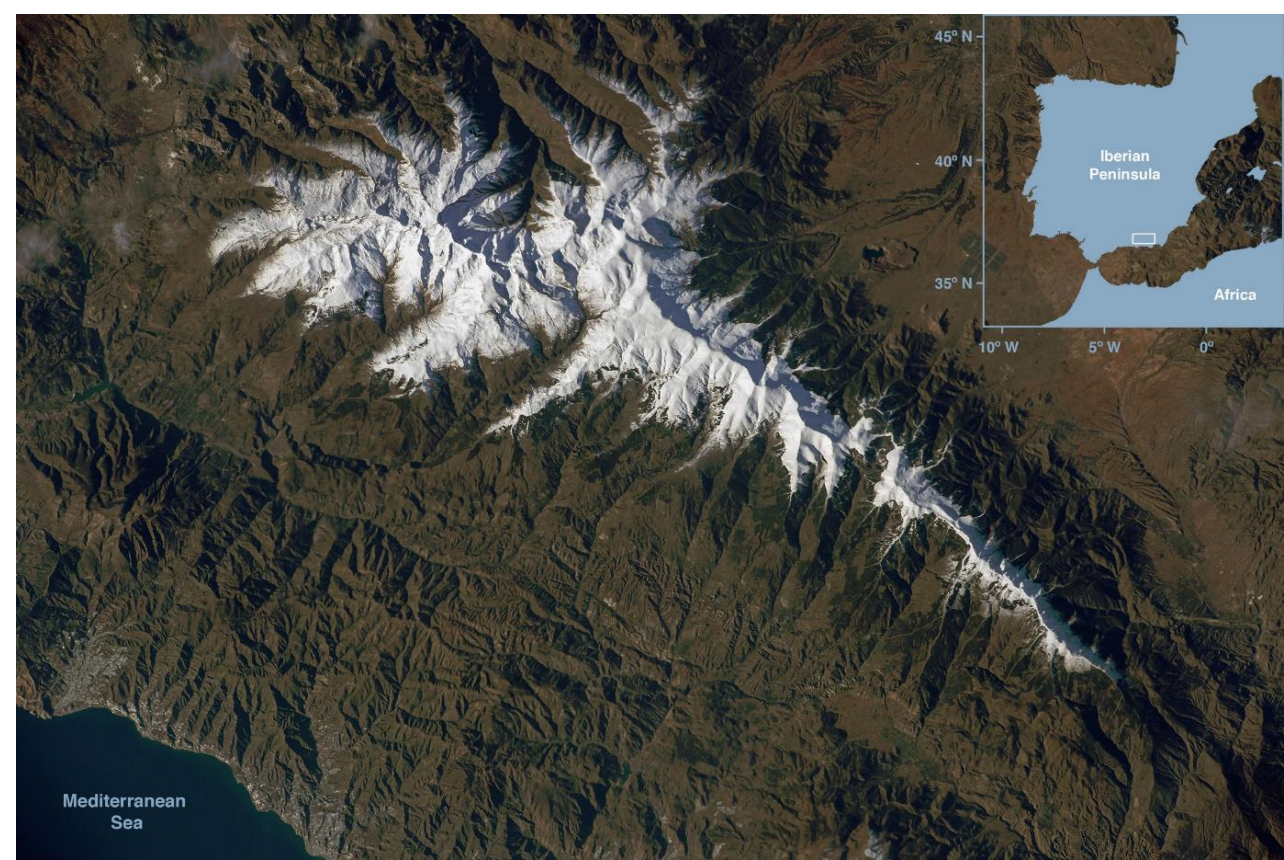

Figure 1. Location (top-right) and remote view of Sierra Nevada mountain region (image from the International Space Station took in December 2014; courtesy of "Earth Science and Remote Sensing Unit, NASA Johnson Space Center"). 
https://doi.org/10.5194/essd-2019-198

Preprint. Discussion started: 7 February 2020

(c) Author(s) 2020. CC BY 4.0 License.
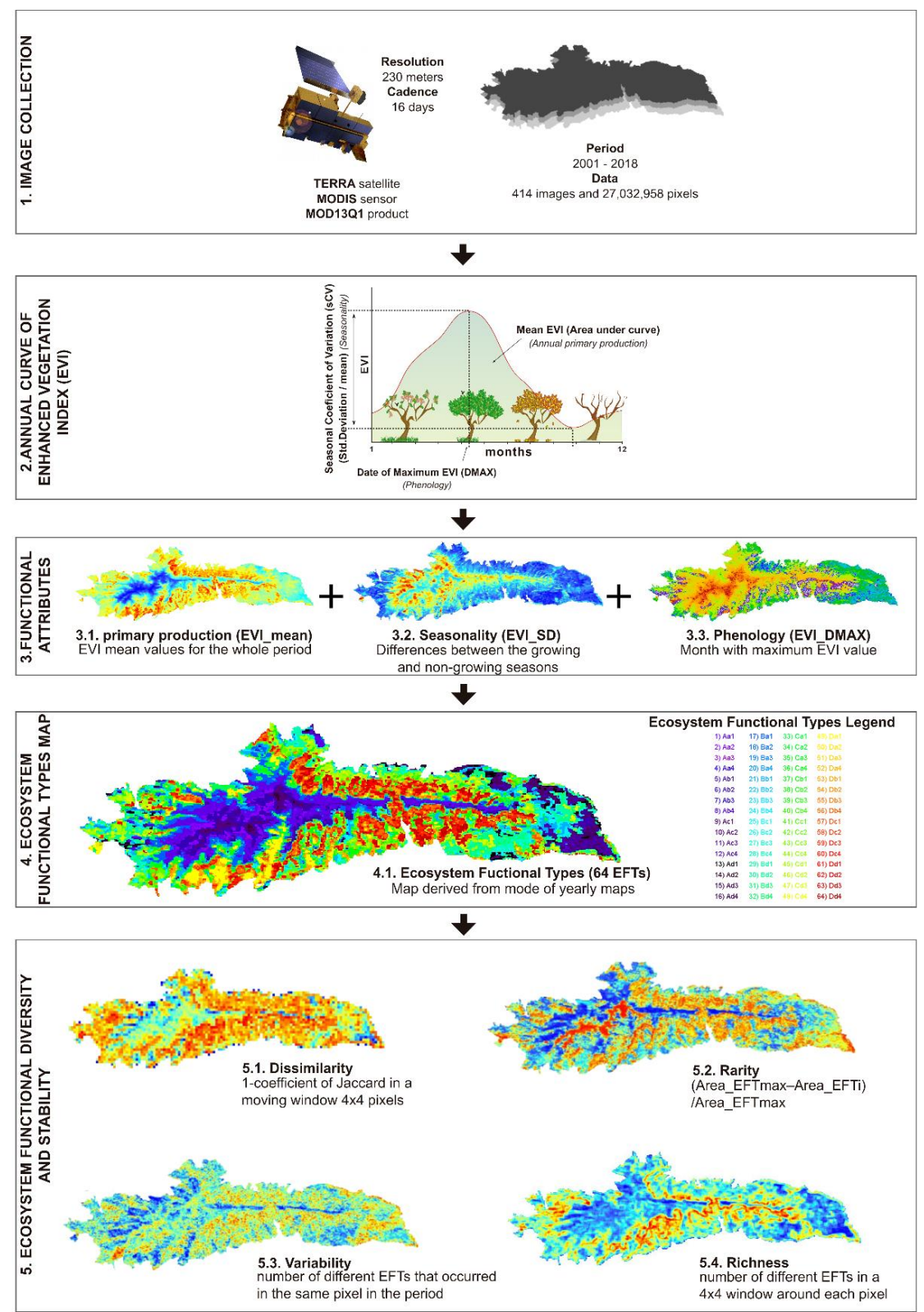

Figure 2. Workflow to characterize the ecosystem functioning and functional diversity of Sierra Nevada. MODIS (Moderate Resolution Imaging Spectroradiometer) sensor product MOD13Q1 was used aboard NASA's Terra satellite. This product contains images with 16-day temporal resolution ( 23 images per year) and $232 \mathrm{~m}$ spatial resolution from the Enhanced Vegetation Index (EVI). The study period was from 2001 to 2018. Three functional attributes describing ecosystem functioning were calculated from the EVI seasonal curve for each year. The range of values for each attribute was divided into four intervals, resulting in a potential number of 64 TFEs $(4 \times 4 \times 4=64)$. From EFTs, we derived fourth metric related to ecosystem functional diversity (EFT richness and rarity) and ecosystem functional stability (interannual variability and dissimilarity). 


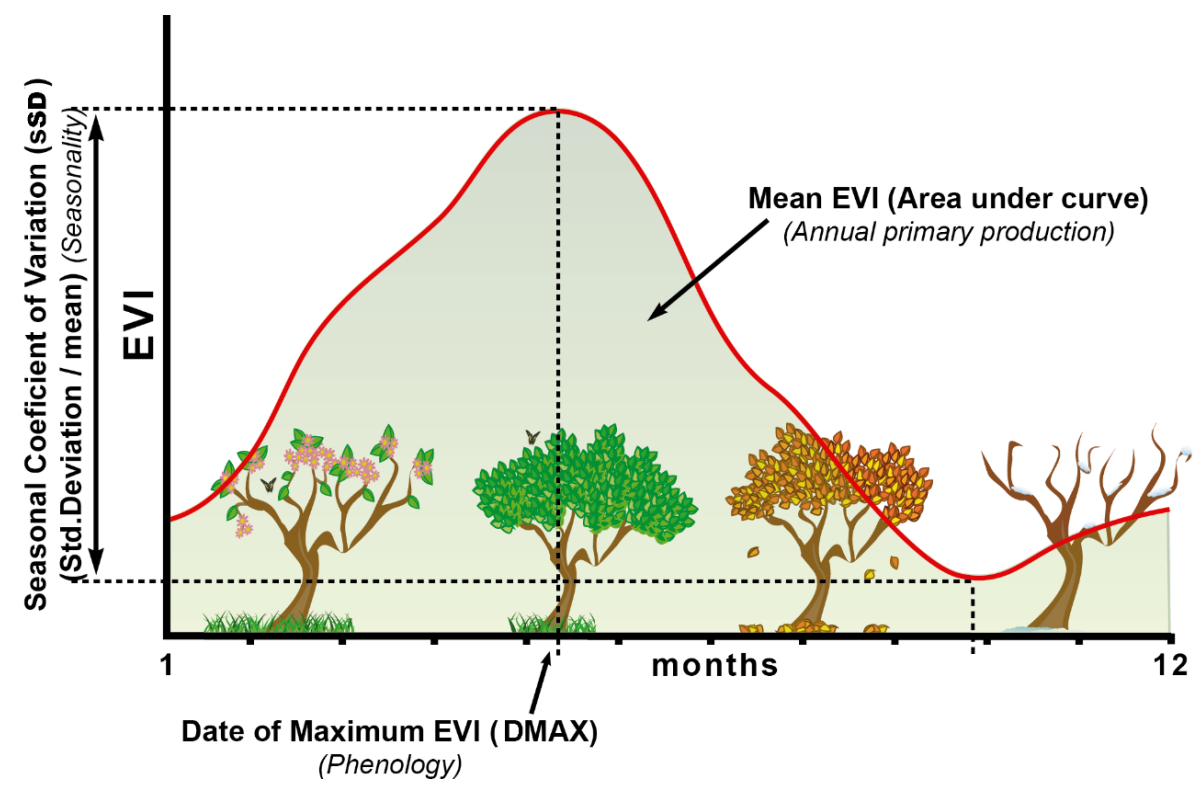

Figure 3: Seasonal dynamics of Enhanced Vegetation Index (EVI) and EVI derived metrics or Ecosystem Functional Attributes (EFAs). The axis "x" corresponds with months and the axis y with EVI values. EFAs were: the annual mean or the area under curve, an estimator of annual productivity (EVI_mean), the EVI seasonal coefficient of variation, i.e. the differences between the minimum and the maximum EVI values, a descriptor of seasonality (EVI_SSD), and the date of maximum EVI, an indicator of phenology (EVI_DMAX). We chose this three EVI metrics or EFAs due to they capture most of the variance of the EVI time series 
https://doi.org/10.5194/essd-2019-198

Preprint. Discussion started: 7 February 2020

(c) Author(s) 2020. CC BY 4.0 License.

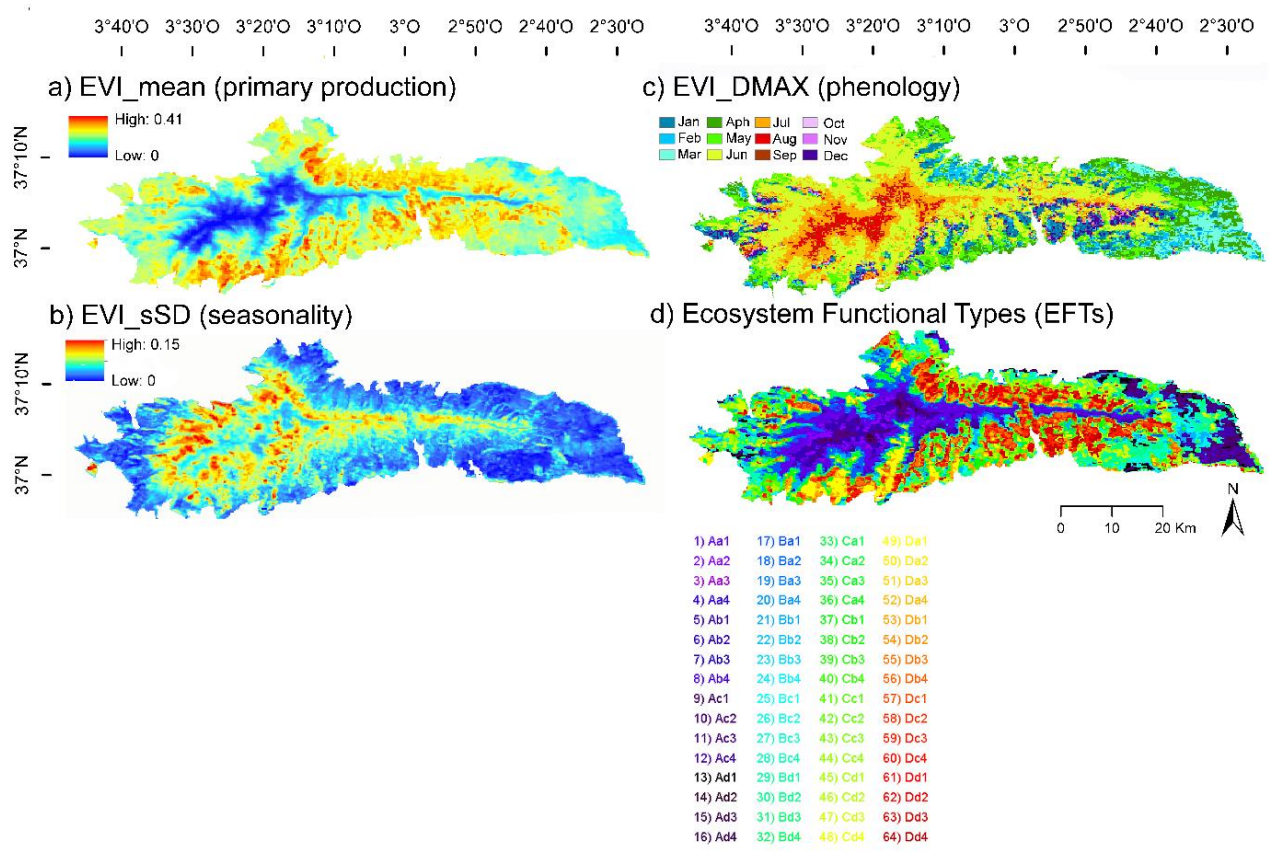

Figure 4. Ecosystem Functional Attributes (a-c) and Ecosystem Functional Types (d) describing the functioning of the canopy based on the Enhanced Vegetation Index (EVI), derived from MOD13Q1TERRA (pixel $\sim 232 \mathrm{~m}$ ) for the period 2001-2018.

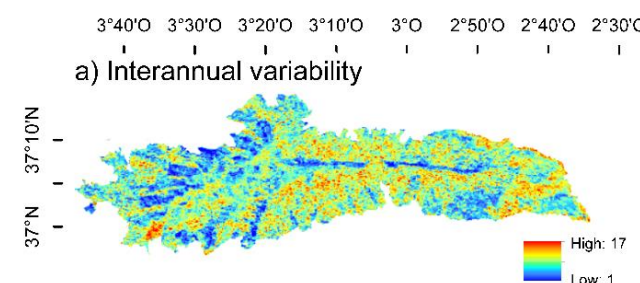

b) Dissimilarity

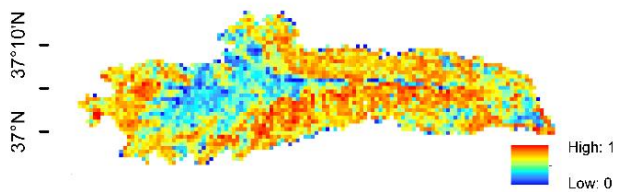

640

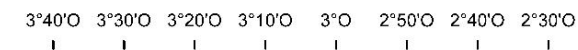

c) E'FT Ríchness

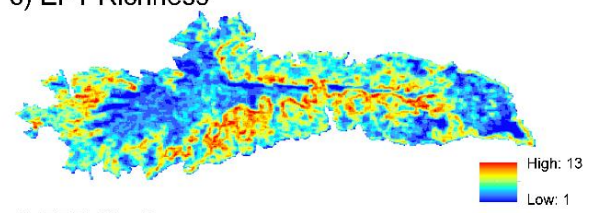

d) EFT Rarity

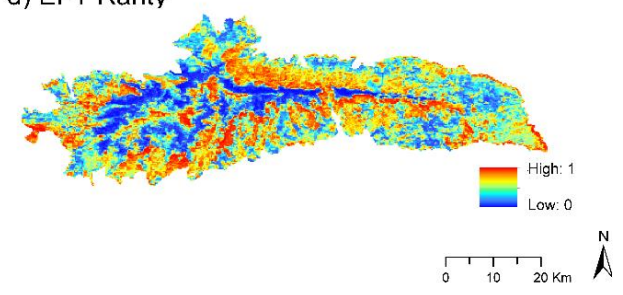

Figure 5. Functional diversity patterns based on the Enhanced Vegetation Index (EVI), derived from MOD13Q1-TERRA for the period 2001-2018. a) EFTs interannual variability for the period; b) EFTs interannual dissimilarity or 1 - Jaccard coefficient for the period; c) Spatial EFT richness patterns from a 4x4 pixel MODIS mobile window ( $\sim 1 \mathrm{~km} 2)$; and d) Spatial EFT rarity patterns. 
https://doi.org/10.5194/essd-2019-198

Preprint. Discussion started: 7 February 2020

(C) Author(s) 2020. CC BY 4.0 License.

Table 1. EFAs range used for identification of EFTs in Sierra Nevada. For EVI_DMAX, the four intervals agreed with the four seasons of the year. For EVI_mean and EVI_sSD, we extracted the first, second, and third quartiles for each year and then calculated the inter-annual mean of each quartile (means of the 18year period).

\begin{tabular}{|c|c|c|c|}
\hline $\begin{array}{l}\text { Ecosystem } \\
\text { Functional } \\
\text { Attribute }\end{array}$ & $\begin{array}{c}\text { Character } \\
\text { code }\end{array}$ & Digit code & Range \\
\hline \multirow{4}{*}{$\begin{array}{c}\text { EVI Mean } \\
\text { (Productivity) }\end{array}$} & A & 100 & $0-0,137$ \\
\hline & $\mathrm{B}$ & 200 & $0,137-0,187$ \\
\hline & $\mathrm{C}$ & 300 & $0,187-0,241$ \\
\hline & $\mathrm{D}$ & 400 & $>0,241$ \\
\hline \multirow{4}{*}{$\begin{array}{c}\text { EVI SD } \\
\text { (Seasonality) }\end{array}$} & $\mathrm{a}$ & 10 & $>0,062$ \\
\hline & $\mathrm{b}$ & 20 & $0,043-0,062$ \\
\hline & $\mathrm{c}$ & 30 & $0,030-0,043$ \\
\hline & $\mathrm{d}$ & 40 & $0-0,030$ \\
\hline \multirow{4}{*}{$\begin{array}{l}\text { EVI MMAX } \\
\text { (Phenology) }\end{array}$} & 1 & 1 & Spring \\
\hline & 2 & 2 & Summer \\
\hline & 3 & 3 & Autumn \\
\hline & 4 & 4 & Winter \\
\hline
\end{tabular}




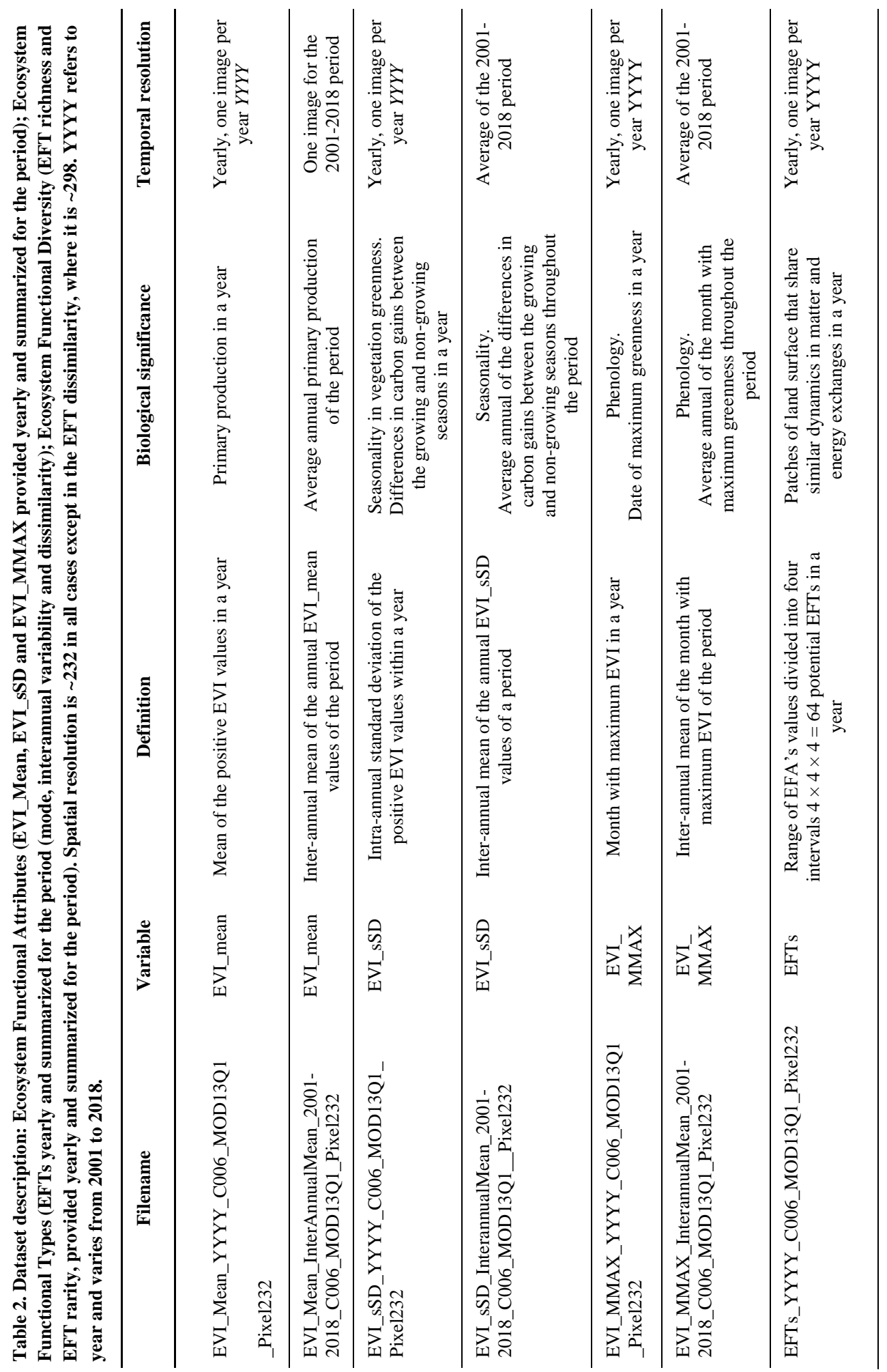




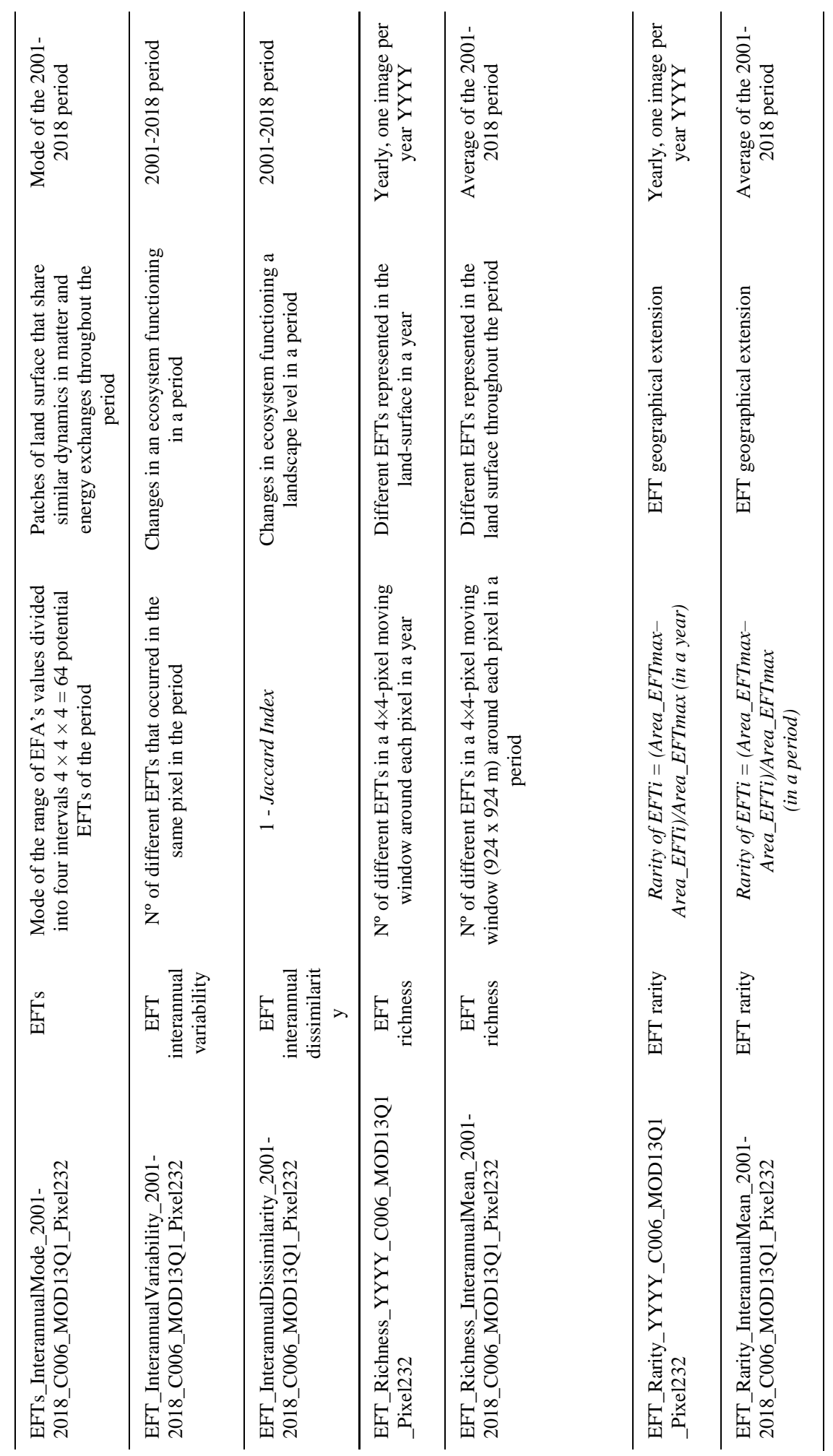

